Vidya Wertta Volume 3 Nomor 2 Tahun 2020

p-ISSN 0852-7776-e-ISSN 2655-7282

https://ejournal.unhi.ac.id/index.php/vidyawertta

\title{
TRANSFORMASI NILAI ETIKA DALAM UPACARA MENDEM SAWA PADA MASYARAKAT BALI AGA DI DESA TRUNYAN KABUPATEN BANGLI
}

\author{
I Nengah Artawan \\ Ni Made Surawati \\ $\underline{\text { artawan@unhi.ac.id }}$ \\ Prodi Pendidikan Agama Hindu \\ Fakultas Pendidikan \\ Universitas Hindu Indonesia
}

\begin{abstract}
ABSTRAK
Tradisi di Desa Trunyan kebanyakan terefleksi dalam kegiatan yadnya. Yadnya ini akan dilandasi dengan keikhlasan tanpa pemrih. Tradisi yang ada di Desa Trunyan banyak memiliki perbedaan dengan desa lainnya. Tentu perbedaan semacam ini bukanlah terletak pada konsepsinya, melainkan hanya menyangkut dengan Desa, Kala, Patra. Salah satu yang akan dikaji dalam artikel ini yakni tradisi mendem sawa. Mendem sawa ada tiga cara yaitu pertama mendem sawa dengan cara tidak dikubur ini khusunya bagi orang Trunyan yang mati wajar, maka di pendem di sema wayah, kedua orang tersebut meninggal belum ketus gigi ini bisa dikatakan masih statusnya anak-anak, maka orang tersebut sawanya di kubur di sema $n g u d a$, ketiga ketika orang itu mati karena ulah pati, atau salah pati, baru orang tersebut sawanya dikubur di sema Bantas. Tradisi mendem sawa pada masyarakat Bali Aga inilah yang ada di Desa Terunyan mengalami transformasi nilai etika. Melihat perkembangan semakin maju dan didukung oleh pariwisata, tentu masyarakat trunyan biasa melakukat aktivitas ke kuburan Terunyan, sekaligus menjadi pemandu wisata.
\end{abstract}


Kata kunci: Transformasi, upacara mendem sawa, Bali Aga

\begin{abstract}
Most of the traditions in Trunyan Village are reflected in their yadnya activities. This Yadnya will be based on sincere selflessness. The traditions that exist in Trunyan Village have many differences with other villages. Of course this kind of difference does not lie in the conception, but only in relation to Desa, Kala, Patra. One thing that will be examined in this article is the tradition of mendem sawa. There are three ways to mendem sawa, firstly mendem sawa by not being buried, especially for the Trunyan people who died naturally, then in the pendem at the sema wayah, the two people died without breaking their teeth grave in sema nguda, thirdly, when a person dies because of starch, or patience, then the person is buried in sema Bantas. The tradition of mendem sawa in the Bali Aga community in Terunyan Village has undergone a transformation of ethical values. Seeing the progressive development and being supported by tourism, of course the Trunyan people usually do activities to the Terunyan cemetery, as well as become tour guides.
\end{abstract}

Key words: Transformation, mendem sawa ceremony, Bali Aga

\title{
I. PENDAHULUAN
}

Bali merupakan pulau yang sangat kaya dengan tradisi, budaya dan adat yang dapat memberikan warna tersendiri serta kekhasan dibandingkan dengan pulau lain di Indonesia. Salah satu hal yang menjadikan tradisi, budaya dan adat itu demikian tertata dan dikelola baik karena semuanya dijiwai oleh ajaran agama hindu. Segala bentuk aktivitas yang berkaitan dengan tradisi, adat dan budaya selalu mengandung nilainilai dan konsep ke-Tuhanan. Pelaksanan tradisi yang ada di Bali tidak sama antara tempat yang satu dengan yang lainnya. Perbedan semacam ini bukanlah terletak pada konsepsinya, melainkan hanya menyangkut soal 
tradisi yang disesuaikan dengan Desa, Kala, Patra. Perbedaan seperti inilah yang memberikan ragam dan aneka jenis tradisi di daerah Bali.

Agama Hindu memiliki fungsi bagi manusia baik untuk dirinya secara individual maupun secara sosial atau kemasyarakatan. Swastika (2006) menyatakan bahwa secara umum manusia beragama karena terdorong oleh beberapa hal yakni: (1) untuk mendapatkan rasa aman; (2) untuk memperoleh perlindungan hidup; (3) untuk menemukan penjelaskan dunia beserta segala hal yang ada di dalamnya; (4) guna untuk memperoleh pembenaran terhadap masalah-masalah kehidupan; (5) guna meneguhkan tata nilai yang terdapat dalam masyarakat; (6) untuk memperoleh kepuasan batin.

Tradisi yang ada di Terunyan lebih di kenal dengan istilah Dresta, yaitu bagian budaya yang merupakan kebiasaan hidup dan kehidupan yang dilaksanakan dan diteruskan secara turun-temurun dalam suatu keluarga, suku, bangsa dalam suatu batas wilayah. Karena dilaksanakan, dipelihara, dan dihormati secara turun-temurun, maka tradisi tersebut selalu ditambah dengan kata "luhur", yang menggambarkan bahwa tradisi ini memang luhur/mulia yang diwarisikan dan diturunkan oleh para "leluhur", sebagai suatu konsepsi dan kebiasaan yang luhur. Sehingga patut dilestarikan, dipelihara serta mengamalkan nilai-nilai tradisional agar tetap tumbuh dan berkembang.

Di dalam penyelengaraan tradisi medem sawa pada masyarakat Bali Aga seperti ini sudah tentu ada perbedaan yang cukup menjolok dengan daerah lain. Setiap daerah ditanah air memiliki ciri khas tertentu sesuai dengan adat-istiadat dan kepercayaan yang berlaku di masing-masing daerah. Adanya perbedaan dalam adat-istiadat akan menimbulkan perbedaan dalam tata cara prosesi pelaksanaan mendem Sawa. Bahkan perbedaan ini sangat menonjol dan terlihat jelas dalam setiap pelaksanaan upacara keagamaan. Ini disebabkan karena penduduk desa Bali Aga yang ada di Terunyan di yakini sebagai penduduk Bali Mula atau Bali Aga yaitu masyarakat yang baru sedikit kena pengaruh kebudayaan Hindu.

Selain di Desa pakraman Terunyan kelompok ini mendiami desadesa pedalaman seperti Kedisan, Abang Songan dan, Desa Tenganan Pegringsingan Bali Age (Bali Mula) dengan kehidupan orang dalam hindu dalam merefleksikan keyakinannya melalui tradisi-tradisi lokal, sepertinya mendem sawa ada tiga cara yaitu pertama mendem sawa dengan cara tidak 
dikubur, itu bagi orang yang meningal sewajarnya yang di kubur di setra wayah, kedua ketika orang itu mati karena ulah pati, salah pati, dan alih pati baru orang tersebut sawanya di Pendem atau dikubur dan yang ketiga ketika orang tersebut meninggal belum ketus gigi ini bias dikatakan masih setatusnya anak-anak maka orang tersebut maka sawanya dipendem di setra bajang.

Salah satu tradisi desa adat Terunyan yang masih dijaga hingga sampai saat ini adalah tradisi upacara kematian yaitu pada saat mendem sawa yang tidak ada bandingannya dengan daerah lain di Bali. Di Desa Terunyan mayat mereka taruh begitu saja di sebuah areal hutan atau di setra wayah. Anehnya, mayat itu tak akan mengeluarkan bau busuk walaupun sudah disana selama berbulan-bulan. Pada tradisi upacara mendem sawa pada masyarakat Bali Aga yang ada di Desa Terunyan dulu seorang wanita atau bagi perempuan tidak diijinkan untuk ikut mengantarkan jenasah atau mayat (Sawa) ke kuburan Desa Terunyan, melihat kemajuan teknologi yang berasal dari transportasi khususnya but yang di pakai nyebrang dari rumah warga Desa Terunyan menuju setra Terunyan tentu wanita atau perempuan bias ikut ke setra untuk mengantarkan jenasah atau sawa, hal ini tentu tepatnya dilakuakan juga pada waktu ngeroras.

\section{PEMBAHASAN}

\section{A. Transformasi Nilai Etika}

Transformasi adalah sebuah proses perubahan secara berangsurangsur sehingga sampai pada tahap ultimate, perubahan yang dilakukan dengan cara memberi respon terhadap pengaruh unsur eksternal dan internal yang akan mengarahkan perubahan dari bentuk yang sudah dikenal sebelumnya melalui proses menggandakan secara berulang-ulang atau melipatgandakan. Etika adalah ilmu yang menjelaskan tentang arti baik dan buruk, menerangkan apa yang seharusnya dilakukan oleh manusia, menyatakan tujuan yang harus dituju oleh manusia dalam perbuatan mereka dan menunjukkan jalan untuk melakukan apa yang seharusnya diperbuat.

Donder (2010 : 578) menjelaskan bahwa nilai etika adalah nilai kebaikan dari tingkah laku manusia yang menjadi sentral persoalan. Maksudnya adalah tingkah laku yang penuh tanggung jawab, baik 
tanggung jawab terhadap diri sendiri, masyarakat, maupun Tuhan sebagai Sang Pencipta. Manusia dilengkapi dengan kemampuan berwiweka, maka dari itu diharapkan bisa memilih yang baik dan benar, sehingga mampu menghindari yang buruk dan salah. Manusia harus bisa mengendalikan diri dalam segala hal, baik dalam berpikir, berkata dan berbuat, agar dapat tercapai hal-hal yang baik dalam kehidupan. Pengendalian diri yang ditekankan dalam hal ini adalah mampu menguasai sifat marah, yang dalam ajaran Agama Hindu disebut dengan krodha. Pengendalian diri untuk tidak marah (akrodha). Seperti sebuah sloka yang terdapat dalam Kitab Sarasamuccaya 109, sebagai berikut.

\section{Dharmārthahetoh kșamatastitikșoh șāntiruttama, lokasangrahaṇarthām vai sa tu dhairyena labhyate.}

Artinya:

Orang yang tahan sabar menghadapi keadaan panas, maupun dingin, untuk berhasilnya pelaksanaan tugas dalam bidang dharma dan artha, bersabarlah ia terhadap ucapan-ucapan yang baik maupun buruk, maka tercapailah lenyapnya nafsu murka, disebabkan ketetapan hatinya ; karenanya tertariklah perhatian masyarakat dunia olehnya. Dari kutipan sloka tersebut bahwa manusia harus memiliki rasa yang sabar terhadap perubahan, sebab perubahan tradisi nilai etika itu belum tentu membawa dampak yang positif.

\section{B. Tradisi Upacara Masyarakat Bali Aga di Desa Terunyan}

Tradisi adalah hasil cipta dan karya manusia, material, kepercayaan, khayalan, kejadian yang diwariskan dari satu generasi ke generasi berikutnya. Istilah tradisi adalah kebiasaan yang diwariskan dari satu generasi ke generasi berikutnya secara turun-temurun. Kebiasaan yang diwariskan mencakup berbagai nilai budaya, yang meliputi adat-istiadat, sistem kesenian, sistem kepercayaan yang dilakukan oleh masyarakat Bali Aga di Desa Terunyan khusunya pada tradisi upacara mendem sawa. berdasarkan hal tersebut dapat disimpulkan bahwa tradisi adalah kebiasaan keagamaan yang diwariskan oleh leluhur dan dilaksanakan secara turun- 
temurun oleh masyarakat Bali Aga di Terunyan serta mengadung nilainilai keagamaan yang bisa dijadikan pedoman dalam kehidupan.

Upacara adalah serangkaian tindakan atau perbuatan yang terikat pada aturan tertentu berdasarkan adat istiadat, agama, dan kepercayaan. Upacara adat adalah suatu upacara yang dilakukan secara turun-temurun yang berlaku di suatu daerah. Dengan demikian, setiap daerah memiliki upacara adat sendiri-sendiri. Upacara pada dasarnya merupakan bentuk perilaku masyarakat yang menunjukkan kesadaran terhadap masa lalunya. Masyarakat menjelaskan tentang masa lalunya melalui upacara. Melalui upacara, kita dapat melacak tentang asal usul baik itu tempat, tokoh, sesuatu benda, kejadian alam. Dalam Manawa Dharmasastra Bab II, sloka 6 dijelaskan mengenai acara agama sebagai berikut.

"wedo khilo dharma mulam, smrti sile ca tadvidam, Acara's ca iwa sadhunam, atmanastutirewa".

Artinya:

Weda Sruti merupakan sumber utama daripada dharma (agama Hindu), kemudian Smerti, setelah itu Sila, Acara dan Atmanastuti.

Ajaran agama Hindu dibangun dalam tiga kerangka dasar, yaitu tattwa, susila, dan acara agama. Ketiganya adalah satu kesatuan integral yang tak terpisahkan serta mendasari tindak keagamaan umat Hindu (Putra, 2003). Tattwa adalah aspek pengetahuan agama atau ajaran-ajaran agama yang harus dimengerti dan dipahami oleh masyarakat terhadap aktivitas keagamaan yang dilaksanakan. Susila adalah aspek pembentukan sikap keagamaan yang menuju pada sikap dan perilaku yang baik sehingga manusia memiliki kebajikan dan kebijaksanaan, wiweka jnana.

Sementara itu aspek acara adalah tata cara pelaksanaan ajaran agama yang diwujudkan dalam tradisi upacara sebagai wujud simbolis komunikasi manusia dengan Tuhannya. Acara agama adalah wujud bhakti kehadapan Ida Sang Hyang Widdhi Wasa dan seluruh manifestasi-Nya. Pada dasarnya acara agama dibagi menjadi dua, yaitu upacara dan upakara. Upacara berkaitan dengan tata cara ritual, seperti tata cara sembahyang, hari-hari suci keagamaan (wariga), dan rangkaian upacara 
(eed). Sebaliknya, upakara adalah sarana yang dipersembahkan dalam upacara keagamaan.

Dalam fenomena keberagamaan Hindu di Bali, acara agama tampaknya lebih menonjol dibandingkan dengan aspek lainnya. Acara agaa yang seringkali juga disebut upacara atau ritual keagamaan merupakan pengejawantahan dan tattwa dan susila agama Hindu. Acara agama meliputi keseluruhan dari aspek persembahan dan bhakti kepada Tuhan Yang Maha Esa/Ida Sang Hyang Widhi Wasa yang disebut yadnya. Pada dasarnya yadnya dalam agama Hindu dapat dibagi menjadi dua, yakni nitya karma dan naimittika karma. Nitya yadnya adalah yadnya yang dilaksanakan sehari-hari, misalnya yadnya sesa atau mesaiban. Sebaliknya, naimittika yadnya adalah yadnya yang dilaksanakan secara berkala atau pada waktu-waktu tertentu, misalnya pada saat piodalan, rerahinan, dan hari raya keagamaan Hindu lainnya (Tim, 2005).

\section{Konsep Mendem Sawa Pada Masyarakat Bali Aga}

Mendem sawa atau penguburan jenazah adalah sebuah upacara pemakaman. Menurut umat Hindu di Bali dalam naskah lontar Yama Tattwa berkaitan dengan mendem sawa disebutkan bahwa apabila manusia itu sudah mati atau sudah meninggal harus dilakukan mendem sawa. Manusia mati berarti hubungan dengan dunia nyatanya telah putus, ia dikatakan kembali ke alam baka atau ke akhirat. Ida hyang Widhi atau Tuhan Yang Maha Esa, sang pencipta kelahiran dan kematian yang berwenang menentukan status batas usia, yang tidak dapat diramal oleh manusia biasa, kapan waktunya yang tepat seseorang berpulang kedunia akhirat.

Landasan atau latar belakang filosofis adanya kematian adalah agar ragha sarira yang berasal dari unsur prthiwi sementara dapat merunduk pada prthiwi dulu. Yang secara ethis dilukiskan agar mereka dapat mencium bunda prthiwi. Namun perlu diingatkan bahwa pada prinsipnya setiap orang mati harus segera di aben - jenazahnya dibakar. Bagi mereka yang masih memerlukan waktu menunggu sementara, maka sawa (jenasah) itu harus di pendhem (dikubur) dulu. Dititipkan pada Dewi penghuluning Setra (Dewi Durga). Kalau upacara mendem sawa tidak dilaksanakan dalam kurun waktu yang cukup lama, badan kasarnya akan 
menjadi bibit penyakit, yang disebut Bhuta Cuwil, dan Atmanya akan mendaptkan Neraka, seperti dijelaskan:

"Yan wwang mati mapendhem ring prathiwi salawasnya tan kinenan widhi-widhana, byakta matemahan rogha ning bhuana, haro haro gering mrana ring rat, etemahan gadgad"

Artinya

"kalau orang mati ditanam pada tanah, selamanya tidak diupacarakan diaben, sungguhnya akan menjadi penyakit bumi, kacau sakit mrana di dunia, menjadi gadgad atau tubuhnya. (lontar Tatwa Loka Kertti, lampiran 5a terbitan Paramita: Surabaya, 1999).

Desa Bali Aga pada umumnya terletak di daerah-daerah pegunungan yaitu suatu desa yang jauh dari daerah perkotaan. Letaknya relatif sulit untuk dijangkau dan terisolir. Masyarakat desa Bali Aga sangat tertutup dan sangat kuat mempertahankan adat tradisinya, sertasulit menerima gagasan-gagasan yang datang dari luar desa (Kontjaraningrat, 1989). Tidak mengenal sistim pelapisan sosial atas dasar kasta, seperti: Brahmana, Kasatria, Wesya, dan Sudra (Bagus,1971, Wiana dan santri, 1993) hal itu tidak berlaku. Dalam masyarakat Bali Aga sistem pelapisan sosial yang di, Kasatria, Wesya, dan Sudra. Dalam masyarakat Bali Aga sistem pelapisan sosial yang diberlakukan adalah atas dasar prinsip kesamaan (Kesamen) dan perbedaan tingkatan didasarkan atas senioritas (Uluapad).

\section{Proses Transformasi Tradisi Mendem Sawa Di Desa Terunyan}

Proses mendem sawa di Desa Terunyan pada masyarakat Bali Aga ini sangat sederhana praktis dan simpel namun tidak mengurangi arti dan makna. Jika dilihat dari jenis upakara-nya sudah banyak mengarah ke sastra. Sebenarnya masyarakat Bali Aga ini belum ada pengaruh terhadap budaya luar, tetapi harus tetap berlandasan dengan tri kerangka dasar Agama Hindu. Selanjutnya (Titib, 2003:2). Agama Hindu merupakan agama yang tertua di dunia, ajaran-ajaranya bersumber pada kitab suci Weda yang merupakan wahyu Tuhan Yang Maha Esa. Bila seseorang 
secara mantap mengikuti semua ajaran agama yang bersumber pada sabda suci Tuhan Yang Maha Esa itu, maka akan diperoleh ketentraman dan kebahagiaan hidup yang sejati yang disebut "Moksartam jagadhita ya ca iti dharma.

Salah satu ajaran yang terpenting dan merupakan dasar atau landasan bagi umat Hindu dalam pelaksanaan suatu aktivitas keagamaan, adalah ajaran Tri Kerangka Dasar Agama Hindu yang berisikan Tattwa, Etika dan Upacara. Dimana peranan ketiga hal tersebut tidak pernah lepas dalam pelaksanaan suatu kegiatan atau aktifitas agama Hindu. Seperti dalam bukunya Suhardana disebutkan: "Barang siapa yang ingin mendalami dan mempelajari agama Hindu tersebut hendaknya memahahami betul ketiga kerangka dasar agama Hindu itu yaitu Tattwa, Etika dan Upacara" (Sudarsana, 2007).

Tattwa, Etika dan Ritual (Upacara) merupakan satu kesatuan yang utuh yang harus dilaksanakan secara seimbang dalam melaksanakan suatu aktivitas agama Hindu. Karena ketiga aspek ini saling melengkapi satu dengan yang lainnya. Kalau salah satu dari ketiga aspek tersebut tidak dilaksanakan dengan baik, maka tujuan dari agama Hindu yaitu "Moksartam jagadhita ya ca iti dharma" tidak akan tercapai dengan sempurna. Sehingga dalam setiap melaksanakan aktivitas agama Hindu terutama dalam hal Yajna atau persembahan suci tentu tidak pernah lepas dari konsep Tri Kerangka Dasar Agama Hindu pada masyarakat Bali Aga di Desa Terunyan.

\section{Proses Pembuatan Sarana dan Upakara}

Sehari sebelum dilaksanakannya upacara mendem sawa pada masyarakat terunyan akan dilakukan proses pembuatan sarana prasarana dan upakara (banten) yang dipergunakan dalam upacara Mependem untuk pembuatan sarana baik itu tempat pengusungan jenazah, dan tempat pelindung sawa di setra trunyan (ancak saji) disiapkan secara bergotong royong oleh masyarakat Desa Terunyan. Sedangkan untuk pembuatan upakara (banten) dibuat oleh orang yang membidangi hal tersebut (serati banten). 


\section{Tata Cara Pemendeman Sawa di Desa Terunyan}

Sehubungan dengan kepercayaan orang Terunyan mengenai penyakit dan kematian, maka cara pemakaman orang Terunyan ada dua macam yaitu, (1) meletakan jenasah di permukaan tanah atau di udara terbuka (exsposure) atau oleh orang Bali Hindu disebut dengan istilah Mepasah; dan (2) dikubur kedalam tanah (inhumation). Mereka yang telah di-mepasah-kan adalah mereka yang pada waktu matinya tidak mengalami cacat fisik atau dengan istilah meninggalnya normal dan termasuk mereka yang telah berumah tangga, mereka yang masih bujangan dan anak kecil yang telah meketus, yaitu telah tanggal gigi susunya.

Mereka yang meninggal dengan secara tidak wajar, seperti dibunuh dan bunuh diri, juga dikubur. Demikian juga dengan anak-anak kecil yang pada waktu meninggal belum meketus, atau belum tanggal gigi susunya, jenazah mereka dikubur. Oleh karena itu untuk keperluan tersebut di Desa Terunyan disediakan tiga tempat pemakaman: (1) Sema Wayah, (2) Sema Nguda, dan (3) Sema Bantas. Sema Nguda dipergunakan bagi kedua jenis pemakaman yaitu baik mepasah maupun penguburan.

\section{Pemendeman Sawa Di Setra Wayah}

Sema Wayah adalah tempat pemakaman secara mepasah bagi orangorang yang pada waktu meninggalnya sudah kawin dan matinya normal, artinya karena sakit biasa, atau mati tua. Sema Bantas adalah tempat pemakaman secara mengubur bagi orang yang sudah kawin atau belum, anak-anak maupun orang muda dan orang tua yang meninggalnya tidak wajar atau tubuhnya cacat. Sema Wayah dipergunakan untuk pemakaman jenis mepasah (exporsure), sema wayah ini atau setra tua terletak di Desa Terunyan, ketika ada masyarakat Desa Terunyan yang meningal karena sudah tua, mati karena sakit, dan anggota tubuhnya tidak cacad, bisa dikatakan manusia yang normal, bila saat dia meninggal maka mayatnya atau sawanya di pendem atau di kubur di setra wayah. Proses dari pemendeman ini menunggu dari arahan para pemangku atau penglingsir masyarakat Desa Terunyan, yang di sebut di sana tentu Jero Penyarikan Puji, inilah yang berhak memberikan keputusan untuk memberikan abaaba dalam proses pemendeman sawa pada masyarakat Bali Aga di Desa Terunyan. 
Letak Sema Wayah di suatu belongan yang terletak di sebelah utara belongan Terunyan (Desa Induk Terunyan). Karena pemakaman ini adalah yang terpenting secara upacara ke agamaan, karena disinilah upacara kematian tahap kedua dilakukan, maka dibagian utara daerah pemakaman ini telah didirikan sebuah Pura Dalem, yang menurut kepercayaan orang Terunyan adalah pintu gerbang menuju ke kawah, yaitu dunia orang mati, yang telah di-aben-kan. Sema Nguda terletak disuatu belongan sempit yang sukar dicapai, karena pantainya agak curam. Belongan ini terletak diantara belongan Terunyan (Desa Induk Terunyan) dan belongan Sema Wayah.

\section{Pemendeman Sawa Di Sema Nguda}

Sema Nguda adalah pemakaman khusus bagi orang-orang yang belum kawin dan anak-anak yang sudah meketus yang dilakukan secara Mepasah dan di samping itu juga dipergunakan sebagai tempat pemakaman bagi anak-anak bayi yang belum Maketus tetapi secara penguburan. Hanya saja tempatnya untuk mepasah dilakukan di area lapangan terbuka, sedangkan untuk penguburan di kaki lereng bukit batu. Perbedaan penguburan di Sema Bantas dengan penguburan di Sema Nguda adalah bagi anak-anak bayi yang belum meketus maka jenazahnya tidak di kubur dengan tanah melainkan dengan batu.

Setra muda ini tentu secara khusus untuk setra anak-anak secara jelas bahwa bagi masyarakat Desa Terunyan, sema nguda ini khusus orang meninggal di bawah umur seperti anak-anak atau anak yang belum ketus gigi. Masyarakat Desa Terunyan yang mempunyai anak meninggal atau mati belum ketus gigi atau bias dikatakan mati karena di bawah umur. tentu masyarakat Bali Aga Desa Terunyan mendem sawanya di Serta Nguda.

\section{Pemendeman Sawa Di Sema Bantas}

Letak Sema Bantas yang asli adalah di perbatasan belongan Cemara Landung dan Desa Abang Batu Dinding, tetapi sebagai perkembangan, di Dusun Puseh yang yang terletak disebelah tenggara Desa Induk Terunyan, yaitu jauh di luar kawah Gunung Batur Purba, juga dibuat orang semacam Sema Bantas baru. Fungsi Sema Bantas yang baru ini sudah tidak sama 
lagi dengan yang asli, karena di tempat ini walaupun dilaksanakan pemakaman dengan cara mengubur jenazah (inhumation).

\section{PENUTUP}

Dari uraian di atas dapat ditarik kesimpulan bahwa tradisi adalah hasil cipta dan karya manusia, yang diwariskan dari satu generasi ke generasi berikutnya. Istilah tradisi adalah kebiasaan yang diwariskan dari satu generasi ke generasi berikutnya secara turun-temurun. Proses Upacara tradisi mendem sawa di Desa Terunyan pada masyarakat Bali Aga ini sangat sederhana praktis dan simpel namun tidak mengurangi arti dan makna. Jika dilihat dari jenis upakaranya sudah banyak mengarah ke sastra. Sebenarnya masyarakat Bali Aga ini belum ada pengaruh terhadap budaya luar, tetapi harus tetap berlandasan dengan tri kerangka dasar Agama Hindu. Proses mendem sawa ini dilakukan dengan tiga cara yaitu, mendem sawa di setra wayah, setra bantas dan setra nguda.

\section{DAFTAR PUSTAKA}

Bagus, I.G.Ng. 1971, Kebudayaan Bali” Manusia Dan Kebudayaan Di Indonesia (Redaksi Kontjarningrat). Djakarta, Penerbit Dejambatanhal.

Bagus, I.G.Ng. 1994, Kebudayaan Bali" Manusia Dan Kebudayaan Di Indonesia (Redaksi Kontjarningrat). Djakarta, Penerbit Dejambatanhal 284-304.

Donder, I Ketut dan I Ketut Wisarja. 2010. Filsafat Ilmu. Surabaya : Paramita

Gunadha, Ida Bagus. Nanang Sutrisno (ED). 2013. Panca Sradha "Lima Prinsip Keimanan Hindu Indonesia”. Denpasar: Widya Dharma.

Kajeng, I Nyoman. 2010. Sarasamuccaya. Surabaya: Paramita.

Koentjaraningrat. 1980. Sejarah Teori Kebudayaan. Jakarta: Gramedia. . 2009. Pengantar Ilmu Antropologi. Jakarta: Rineka Cipta.

Lontar Tatwa Loka Kertti, lampiran 5a terbitan Paramita: Surabaya, 1999).

Sudarsana, Ida Bagus Putu. 2010. Himpunan Tetandingan Upakara Yadnya. Denpasar: Yayasan Dharma Acarya 
Sudarsa, I Nengah, (2007). Dalam tesisnya yang berjudul" Kedudukan Dan Fungsi Prewayah Dalam Sisitim Pemerintahan Masyarakat Bali Aga Di Desa Adat Timbrah Karangasem. Universitas Hindu Indnesia (UNHI)

Sanjaya, Putu. 2011. Filsafat Pendidikan Agama Hindu. Surabaya : Penerbit \& Percetakan Paramita

Swastika, I Dewa Gede. 2006. Murdha Citta Dalam Sarasehan Bidang Agama, Adat, dan Budaya. Denpasar: Badan Diklat Provinsi Bali.

Tim Penyusun. 2005. Kamus Istilah Agama Hindu. Denpasar : Proyek Peningkatan Sarana dan Prasarana Kehidupan Beragama.

Putra, I. Gst. Ag, 2003, Panca Yadnya, Pemerintah Propinsi Bali, Kegiatan Peningkatan Sarana dan Prasarana Kehidupan Beragama, Denpasar 